\title{
Nivelamento de matemática: uma alternativa para o ensino remoto
}

\author{
Leveling mathematics: an alternative for remote \\ teaching
}

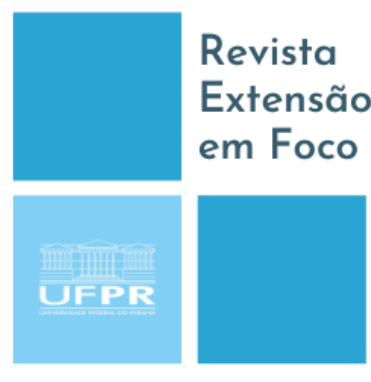

ISSN $2358-7180$

\author{
Danilene Gullich Donin Berticelli ${ }^{1}$, Simone Francisco Ruiz ${ }^{2}$, Aline Mendes Lopes ${ }^{3}$, Ana \\ Maria Batista ${ }^{4}$, Bárbara Strey Wagner ${ }^{5}$, Bruna Larissa Tuom ${ }^{6}$, Eddy Oliveira de \\ Almeida $^{7}$, Renan Roberto de Marchi ${ }^{8}$, Taís de Souza Silva9
}

\begin{abstract}
RESUMO
O presente trabalho pretende relatar a experiência vivenciada no Curso de Extensão Nivelamento de Matemática para o ensino Superior, que foi adaptado para o ensino remoto durante o período de pandemia ocasionado pela Covid-19. O curso teve como objetivo auxiliar os alunos das séries finais do ensino médio bem como ingressantes no ensino superior no que diz respeito às dificuldades apresentadas por eles nas disciplinas de matemática que compõe a grade curricular do ensino médio e de graduações. Paralelamente, o curso buscou proporcionar a experiência da docência aos alunos do curso de Licenciatura em Ciências Exatas da UFPR- Setor Palotina em atividades extracurriculares, tendo em vista que estes foram os ministrantes do curso. Com uma proposta inicial organizada para o ensino presencial, o isolamento social imposto pela pandemia implicou na adaptação do curso para a versão remota. Neste contexto, foi necessário repensar as metodologias do curso para que sua realização fosse possível, adaptando-se ao formato virtual, por meio de aulas síncronas realizadas remotamente. Neste formato, a lousa e giz foram substituídos por programas computacionais que auxiliaram na transmissão dos conteúdos através do compartilhamento da tela do computador. A versão remota do curso proporcionou, tanto aos alunos participantes quanto aos que ministraram as aulas, a vivência da sala de aula em um novo formato, o virtual, no qual também foi possível realizar com qualidade o diálogo entre
\end{abstract}

\footnotetext{
${ }^{1}$ Doutorado em Educação. Universidade Federal do Paraná (UFPR), Palotina, Paraná, Brasil. E-mail: danilene@ufpr.br. Orcid: https://orcid.org/0000-0003-3051-4750

${ }^{2}$ Doutorado em Matemática. Universidade Federal do Paraná (UFPR), Palotina, Paraná, Brasil. E-mail: simoneruiz@ufpr.br. Orcid: https://orcid.org/0000-0001-9302-8886

${ }^{3}$ Graduanda em Licenciatura em Ciências Exatas. Universidade Federal do Paraná (UFPR), Palotina, Paraná, Brasil. E-mail: alinemendes@ ufpr.br. Orcid: https://orcid.org/0000-0002-3320-8989

${ }^{4}$ Graduanda em Licenciatura em Ciências Exatas. Universidade Federal do Paraná (UFPR), Palotina, Paraná, Brasil. E-mail: anabatista@ufpr.br. Orcid: https://orcid.org/0000-0003-1937-7265

${ }^{5}$ Graduanda em Licenciatura em Ciências Exatas. Universidade Federal do Paraná (UFPR), Palotina, Paraná, Brasil. E-mail: barbarastrey @ufpr.br. Orcid: https://orcid.org/0000-0002-0962-0236

${ }^{6}$ Graduanda em Licenciatura em Ciências Exatas. Universidade Federal do Paraná (UFPR), Palotina, Paraná, Brasil. E-mail: bruna.tuom@ufpr.br. Orcid: https://orcid.org/0000-0001-7453-883X

${ }^{7}$ Graduando em Licenciatura em Ciências Exatas. Universidade Federal do Paraná (UFPR), Palotina, Paraná, Brasil. E-mail: eddyoliveira@ufpr.br. Orcid: https://orcid.org/0000-0002-9693-6545

${ }^{8}$ Graduando em Licenciatura em Ciências Exatas. Universidade Federal do Paraná (UFPR), Palotina, Paraná, Brasil. E-mail: renanroberto@ufpr.br. Orcid: https://orcid.org/0000-0002-7309-4314

${ }^{9}$ Graduanda em Licenciatura em Ciências Exatas. Universidade Federal do Paraná (UFPR), Palotina, Paraná, Brasil. E-mail: taissouza@ufpr.br. Orcid: https://orcid.org/0000-0002-9129-7609
} 
professor e aluno e auxiliar os participantes em suas dificuldades relacionadas aos conteúdos abordados no curso.

Palavras-chave: Ensino de Matemática. Ensino Remoto. Formação de Professores.

\section{ABSTRACT}

The present work intends to report the experience lived in the Mathematics Leveling Extension Course for Higher Education, which was adapted for remote education during the pandemic period caused by COVID-19. The course aimed to assist students in the final grades of high school, as well as those entering higher education with regard to the difficulties presented by them in the mathematics subjects that make up the curriculum of high school and undergraduate courses. At the same time, the course sought to provide the teaching experience to the students of the Degree in Exact Sciences at UFPR Setor Palotina in extracurricular activities, considering that these were the teachers of the course. With an initial proposal organized for face-to-face education, the social isolation imposed by the pandemic implied the adaptation of the course to the remote version. In this context, it was necessary to rethink the methodologies of the course so that its realization was possible, adapting to the virtual format, through synchronous classes held remotely. In this format, the blackboard and chalk were replaced by computer programs that helped in the transmission of the contents through the sharing of the computer screen. The remote version of the course provided, both the participating students and those who taught the classes, experiences of the classroom in a new format, the virtual one, in which it was also possible to carry out the dialogue between teacher and student with quality and to assist the participants in their difficulties related to the contents covered in the course.

Keywords: Mathematics teaching. Remote Education. Teacher training.

\section{INTRODUÇÃO}

Em tempos de pandemia temos que nos reinventar e nos adaptar ao novo cenário no qual nos deparamos. Isso acontece na vida pessoal e profissional. Desta forma, muitas atividades que eram desenvolvidas no modo presencial foram forçadamente adaptadas para o modo virtual. Neste cenário emergiu o curso Nivelamento de Matemática para o Ensino Superior, que em sua primeira versão aconteceu totalmente de modo presencial, mas que em 2020 foi adaptado para o modo virtual para atender todas as exigências e recomendações governamentais e de órgãos de saúde.

O curso foi ofertado para alunos de graduação da Universidade Federal do Paraná e de outras instituições de ensino, incluindo ensino médio, e teve como objetivo geral reforçar conceitos matemáticos básicos que pudessem nortear as disciplinas de matemática do ensino médio e superior. Teve como objetivo ainda auxiliar os acadêmicos da Universidade Federal do Paraná, dos diversos cursos, no que diz respeito às disciplinas de matemática presentes nas grades curriculares de seus respectivos cursos, pois o conteúdo abordado compreendeu uma matemática básica, necessária para qualquer curso que envolva a área de exatas. Como formadores de professores temos a responsabilidade 
de levar os graduandos a conhecer a realidade da sala de aula e suas adaptações. Neste momento de pandemia a sala de aula transformou-se em uma sala virtual e as atividades passaram a acontecer de forma remota. Por isso precisamos adaptar nossa prática e metodologia para dar continuidade ao curso. Repensar e reinventar a prática pedagógica faz parte da docência. Muitas vezes somos levados a introduzir novos objetivos de aprendizagem, pensar em novas metodologias de ensino buscando situações de aprendizagem que respondam melhor diante das condições impostas. Nesse sentido, o curso buscou proporcionar a prática docente dos alunos do curso de Licenciatura em Ciências Exatas da Universidade Federal do Paraná do Setor Palotina, num cenário completamente diferente ao que eles estavam acostumados, pois eles foram os ministrantes das aulas do curso. Tivemos que preparar uma aula adaptada a realidade virtual, aprendendo a lidar com desafios que o modo presencial não nos apresentava, como a falta de internet, a distância dos alunos, a relação professor e aluno que ficou limitada a uma pessoa falando para uma tela cheia de bolinhas, fatores estes que foram desafiantes no processo, mas que trouxeram muita aprendizagem.

O Nivelamento de Matemática para o Ensino Superior justifica-se diante das dificuldades que são apresentadas pelos acadêmicos nas disciplinas de matemática do ensino superior, onde percebemos que é urgente a necessidade de desenvolver atividades que auxiliem o desempenho acadêmico dos estudantes em matemática. Em sua grande maioria, os alunos que ingressam na universidade e precisam cursar disciplinas como o Cálculo ou que envolvem cálculo, por exemplo, manifestam grandes dificuldades não em relação ao conteúdo novo que lhes é apresentado, mas sim ao que é considerado prérequisito e, portanto, não está previsto na ementa das disciplinas. Muitos alunos que ingressam em cursos de graduação apresentam dificuldades básicas em matemática com operações, frações, funções, conteúdos que são alicerces para conceitos mais complexos. Deste modo, a participação em atividades extracurriculares é uma alternativa para minimizar as dificuldades e diminuir os obstáculos que os alunos enfrentam em conteúdos mais complexos de matemática. Além disso, o curso permite o desenvolvimento de atividades extracurriculares relacionadas à docência, que são fundamentais para os estudantes das licenciaturas. A versão na qual o curso aconteceu possibilitou aos alunos desenvolverem aulas de forma remota, proporcionando uma prática diferente da presencial, trazendo grande aprendizado para estes enquanto futuros professores. 


\section{DESENVOLVIMENTO}

A versão remota do curso Nivelamento de Matemática para o Ensino Superior foi desenvolvida tomando como norte os conteúdos que estavam no planejamento do curso presencial. Desta forma, as aulas que seriam ministradas utilizando como material de apoio lousa e giz, foram readequadas para serem realizadas com as ferramentas disponíveis em uma sala de aula virtual.

A interrupção das atividades acadêmicas de modo presencial provocada pela pandemia do novo coronavírus (SARs Cov-2) fez com que instituições de ensino do mundo inteiro adotassem a modalidade de ensino remoto emergencial, para dar continuidade ao ano letivo (RONDINI et al, 2020). Os professores foram todos lançados para fora da sala de aula, retirados de seu ambiente natural e tiveram que se adaptar a uma nova realidade, a uma nova sala de aula, a sala de aula virtual. Os autores destacam que o ensino remoto emergencial é diferente da modalidade de Educação a Distância (EaD), pois esta conta com recursos e uma equipe multiprofissional preparada para ofertar os conteúdos e atividades pedagógicas, por meio de diferentes mídias e plataformas digitais on-line. Já o ensino remoto busca oferecer acesso temporário aos conteúdos curriculares que seriam desenvolvidos de modo presencial, e com isso não se trata de implantar um sistema estruturado. Em geral conta com os equipamentos e suportes do próprio professor, e não com uma estrutura repleta de equipamentos e recursos tecnológicos. $\mathrm{O}$ ensino remoto é considerado uma alternativa temporária para passarmos por este momento de crise. A educação como um todo foi tomada de surpresa por esta nova realidade, e necessitou adaptar-se forçada e urgentemente (RONDINI et al, 2020).

A UFPR, como muitas universidades do país, adotou este sistema de Ensino Remoto Emergencial (ERE) para ofertar módulos de disciplinas aos alunos matriculados. Esta modalidade nos motivou a retomar a ideia do curso e modificar para o modo virtual, para manter o contato com os alunos e incentivá-los a continuarem conectados com as atividades extracurriculares da Universidade.

No formato remoto, as coordenadoras do curso Nivelamento de Matemática para o Ensino Superior convidaram alguns alunos para participarem do curso como ministrantes, pois necessitávamos de graduandos da licenciatura para ministrar as aulas. Contamos com a participação de sete alunos do curso de Licenciatura em Ciências Exatas 
da UFPR - Setor Palotina. Este grupo era formado por alunos de períodos distintos do curso: quatro alunos do terceiro período, um aluno do quinto e dois alunos do sétimo período. Com os licenciandos selecionados, as coordenadoras marcaram uma reunião para explicar a proposta do curso de nivelamento que deveria ser adaptada para o formato remoto. Nesta adaptação, todo o conteúdo das aulas deveria ser organizado pelos ministrantes em slides, que seriam compartilhados com os participantes durante as aulas. Desta forma, foi sugerido o trabalho em duplas e trios, de modo que os alunos pudessem trabalhar coletivamente. Uma vez que as aulas seriam ministradas de forma remota, o trabalho em equipes facilitaria, entre outros aspectos, o desenvolvimento das aulas no que diz respeito a problemas técnicos que poderiam surgir no momento da aula. Assim, enquanto um aluno explicava o conteúdo, seu parceiro de equipe estava atento sobre detalhes como falha no áudio, acesso dos participantes ao endereço eletrônico (link) da aula e dúvidas que os participantes descreviam no bate-papo (chat) durante as explicações. Além disso, o trabalho em duplas e trio enriqueceu o preparo das aulas, pois os alunos ministrantes tiveram a oportunidade de trocar ideias entre si sobre as melhores formas de apresentar os conteúdos e trabalhar com a resolução de exercícios no formato remoto.

Nenhum dos alunos que ministraram as aulas tinham acesso a equipamentos tecnológicos muito avançados, como mesas digitalizadoras, por exemplo. Deste modo, além dos slides previamente organizados, os ministrantes respondiam algumas dúvidas que necessitavam de cálculos para serem explicadas utilizando o bate-papo (chat) e, para responder questionamentos sobre representações gráficas, utilizavam o GeoGebra, que é um software matemático gratuito que auxilia no ensino de diversos conteúdos da geometria e álgebra, dentre outros.

O material utilizado para nortear as atividades do curso foi a apostila Manual de Sobrevivência em Matemática de autoria de Professor A e Professor B ${ }^{10}$. Este material aborda os conteúdos Polinômios e Funções, que são conteúdos dos quais os alunos da graduação e ensino básico apresentam muita dificuldade. Esta apostila foi disponibilizada gratuitamente para todos os participantes do curso. Nela, além de ser explorado cada assunto a partir de uma situação-problema, há também, ao final de cada seção, uma lista de exercícios sobre os conteúdos abordados, para que os alunos pudessem praticar os conceitos trabalhados nas aulas. Com as duplas e trio formados, o passo seguinte foi

\footnotetext{
${ }^{10}$ Os nomes dos autores foram omitidos pois coincidem com os autores deste artigo.
} 
dividir os conteúdos entre os alunos de modo que cada dupla ou trio ficasse responsável para dar a aula de um determinado conteúdo. As coordenadoras fizeram a distribuição de quais conteúdos deveriam ser trabalhados em cada dia e deixaram que os ministrantes escolhessem quais conteúdos teriam mais facilidade em trabalhar.

O próximo passo foi determinar um período de uma semana para que os grupos preparassem as aulas de acordo com as recomendações das coordenadoras. Em seguida, estes apresentaram as aulas preparadas para as coordenadoras para que estas pudessem avaliar e sugerir melhorias, pois o objetivo principal era que a aula atendesse as necessidades dos participantes. Na última etapa do preparo das aulas, os grupos se reuniram para apresentarem entre si suas aulas, com o objetivo de que a sequência das explicações feitas durante todos os dias do curso fosse a mais clara possível.

Com as aulas preparadas e apresentadas, o curso foi iniciado no dia 05/10/20, tendo duração de 15 dias, com previsão para ser finalizado no dia 21/10/20.

O curso seguiu o cronograma a seguir:

Quadro 1 - Cronograma do curso

\begin{tabular}{|l|l|}
\hline Data & Conteúdo \\
\hline $05 / 10 / 20$ & Polinômios \\
\hline $06 / 10 / 20$ & Resolução de atividades referente a aula do dia $05 / 10 / 20$ \\
\hline $07 / 10 / 20$ & Fatoração \\
\hline $08 / 10 / 20$ & Resolução de atividades referente a aula do dia $07 / 10 / 20$ \\
\hline $09 / 10 / 20$ & Funções: Domínio, Imagem e Gráfico; Operações com funções \\
\hline $13 / 10 / 20$ & Resolução de atividades referente a aula do dia $09 / 10 / 20$ \\
\hline $15 / 10 / 20$ & Função Polinomial; Função Constante; Função do $1^{\circ}$ e $2^{\circ}$ graus \\
\hline $16 / 10 / 20$ & Resolução de atividades referente a aula do dia $15 / 10 / 20$ \\
\hline $19 / 10 / 20$ & Função do $3^{\circ}$ Grau; Função por parte; Função Modular \\
\hline $20 / 10 / 20$ & Resolução de atividades referente a aula do dia $19 / 10 / 20$ \\
\hline $21 / 10 / 20$ & Função Exponencial; Função Logarítmica; Função Trigonométrica \\
\hline
\end{tabular}

Fonte: Próprios Autores (2021).

Pelo quadro pode-se observar que no planejamento das aulas um dia foi reservado para a exposição do conteúdo e o dia seguinte foi planejado para resolução de atividades do conteúdo exposto. Desta forma, os alunos da licenciatura tiveram que planejar a aula composta destes dois momentos: exposição do conteúdo e resolução de exercícios. Todos 
os participantes tinham acesso ao material com as listas de exercícios, uma vez que a apostila que norteou o curso foi enviada em arquivo no formato *.PDF aos seus respectivos endereços eletrônicos (e-mail) individuais. Desta forma, os monitores sempre recomendavam aos participantes que tentassem resolver os exercícios antes da aula. Assim, poderiam acompanhar melhor as resoluções e também teriam a oportunidade de esclarecer suas dúvidas. As aulas foram realizadas via plataforma Google Meet de modo síncrono, onde os alunos participantes podiam participar e fazer questionamentos aos ministrantes. Além disso, as aulas aconteceram sempre no final do dia, das $18 \mathrm{~h}$ às $19 \mathrm{~h}$, para que os alunos que trabalham durante o dia pudessem participar e também tomando o cuidado de não interferir nas atividades acadêmicas noturnas, que normalmente iniciam às $19 \mathrm{~h}$.

O curso contou com a participação de 17 alunos dos cursos de graduação da UFPR Setor Palotina. Como se tratava de um curso de extensão, a chamada estava aberta também para alunos de colégios do município de Palotina, porém não obtivemos inscritos de ensino médio.

Ao finalizar o curso as coordenadoras realizaram uma avaliação com os participantes por meio de formulário virtual com objetivo de investigar como foi a receptividade do curso na versão remota e quais aspectos podem ser melhorados para futuras edições do curso.

O questionário foi elaborado com as seguintes perguntas:

1) Você participou de todas as aulas do curso? Se não, qual foi o motivo da falta?

2) Os dias e horários das aulas foram adequados? Se não, deixe sua sugestão sobre o que seria melhor (aos sábados, por exemplo).

3) Dentre os conteúdos trabalhados no curso, algum deles poderia ter sido melhor explorado? Se sim, qual e por quê?

4) Além dos conteúdos trabalhados no curso, existem outros que você gostaria que fossem abordados? Quais?

5) Qual a sua opinião sobre a realização remota do curso? Seu aproveitamento foi comprometido pelo fato de não ser presencial? Foi possível tirar suas dúvidas durante as aulas tanto quanto seria no presencial? Sinta-se à vontade para expor sua experiência

O que as respostas mostraram foi que a escola pode passar por diversas modificações, mas o modelo presencial ainda é o mais preferível pelos estudantes, pois o contato entre professor e aluno no processo de aprendizagem é fundamental. Mesmo preferindo as aulas presenciais, os participantes entenderam que o formato remoto do 
curso foi uma alternativa temporária para preencher a lacuna aberta pela pandemia, que forçou o distanciamento social.

Os participantes destacaram o esforço dos ministrantes durante as aulas de exercícios, sobre a forma como conseguiram esclarecer as dúvidas que surgiam, contornando a falta de acesso à lousa. Destacaram a qualidade dos slides, com os conteúdos apresentados de maneira clara, cálculos detalhadamente explicados e a utilização do software Geogebra para facilitar a compreensão das representações gráficas. Também elogiaram a qualidade das explicações dos ministrantes, enfatizando a persistência de todos em repetir as explicações sempre que algum aluno solicitasse.

Alguns sugeriram a necessidade de que o curso fosse mais longo, pois gostariam que alguns conteúdos fossem explorados por um tempo maior. Além disso, foi sugerido que houvesse uma ampliação do curso, abordando outros temas do Cálculo Diferencial e Integral, que é uma disciplina presente em todos os cursos de Engenharia, Computação, Matemática, Física e Química, entre outros.

Os ministrantes enfrentaram problemas que estavam fora de seu controle ou dos quais pudessem resolver. Por exemplo, um dia em que uma forte chuva implicou na falta de conexão da internet e o curso teve que ser interrompido. Diante desta situação, os ministrantes tiveram que improvisar, marcar uma nova data para dar continuidade a aula e finalizar a atividade que tinham iniciado. Este tipo de situação é válida, pois a docência é repleta de desafios e surpresas, das quais o professor precisa resolver, muitas vezes no improviso.

Para os ministrantes, foi pedido que fizessem uma auto-avaliação para que as coordenadoras pudessem compreender como foi a experiência de cada um no trabalho proposto. Todos relataram de forma muito positiva a experiência, apesar de preferirem também o ensino presencial. Alguns destacaram que, quando apresentaram as aulas para as coordenadoras, ficaram bastante nervosos, mas que conseguiram superar o nervosismo durante o desenvolvimento do curso e que gostariam de participar de outros projetos extracurriculares que permitissem a prática docente. Um dos ministrantes relatou que participou do curso como aluno no ano anterior, quando foi realizado de forma presencial, e que o curso foi muito importante para ele ao ingressar na universidade. Agora, ministrando as aulas, ele pode ocupar um outro papel e a experiência foi muito enriquecedora, segundo ele.

ASPECTOS DO CURSO- formar o docente a ensinar matemática 
O curso Nivelamento de Matemática para o Ensino Superior aborda dois aspectos relevantes que merecem destaque. O primeiro diz respeito ao ensinar matemática básica para alunos de graduação ou de ensino médio, no sentido de reforçar conteúdos que já foram apresentados. O segundo nos faz olhar para a formação do professor e as oportunidades que o graduando tem de vivenciar a docência ao longo do curso, não limitando-se aos estágios obrigatórios.

Não parece que os dois aspectos acima se relacionam, mas a formação do professor de matemática está totalmente ligada ao ensinar matemática para os alunos. Ao professor cabe receber a formação completa, formada pelos saberes a e para ensinar, de modo que tenha condições de mobilizar as ferramentas adequadas para ensinar matemática.

Qual a relevância de um curso de Nivelamento de Matemática? Qual a necessidade de ensinar/reforçar matemática básica para alunos que ingressam na graduação, ou para alunos que estão finalizando o ensino médio? Não seria correto que estes alunos, ao finalizarem o ensino médio ou a graduação tivessem os conhecimentos necessários e básicos de matemática? Correto seria, mas em geral percebe-se que na prática não é o que acontece. O que se percebe é que, cada vez mais os alunos chegam com déficit em matemática básica no final do ensino médio e ao ingressarem na graduação. Queremos destacar que nosso objetivo não é buscar culpados para esta situação, mas sim, pensar em ações que possam minimizar esta problemática. Esta situação de defasagem em matemática básica, não é um problema isolado que percebemos aqui no Setor Palotina da UFPR, mas estudos de outros pesquisadores indicam tratar-se de uma situação que acontece em outras instituições. Zancan (2017) relata que como professora de Cálculo I em cursos de graduação, encontrava dificuldade de ensinar conteúdos como funções, derivadas de funções, limites e equações, pois os alunos apresentavam dificuldade em aritmética básica, especialmente ao operar com frações e potências.

As dificuldades apontadas por Zancan (2017) são exatamente as mesmas que encontramos nos anos iniciais nos cursos de graduação nos quais lecionamos. Associado a isso, recebemos demandas das escolas no sentido de ofertar cursos de matemática básica, pois os estudantes estão finalizando o Ensino Fundamental II e o Ensino Médio sem dominar a matemática básica. Assim como Zancan (2017) percebemos que esta dificuldade em matemática básica compromete a aprendizagem de outros conteúdos, tornando as aulas de Cálculo I e Cálculo II desinteressantes, maçantes e sem significado 
para os alunos. Por esta razão, entendemos que investir na formação básica em matemática dos estudantes poderia ser uma tentativa de minimizar este problema. Entendemos também tratar-se de uma atitude paliativa, pois resolve um problema pontual, não tratando da problemática dos estudantes como um todo, sem discutir outras áreas do conhecimento que apresentam também seus déficits. De qualquer forma o curso permitiu aos alunos que apresentavam dificuldade, melhorar os conhecimentos básicos oferecendo meios para poderem evoluir em conteúdos mais aprofundados, visando a matemática da graduação.

Outro aspecto relevante do curso diz respeito à formação de docentes. O Curso de Licenciatura em Ciências Exatas do Setor Palotina forma docentes nas áreas de Química, Matemática ou Física. São dois anos de conhecimentos gerais nestas três áreas e na área de ensino e mais dois anos de curso focando em uma área específica, Física, Química ou Matemática. Como professoras formadoras de professores entendemos a necessidade de inserir estes futuros docentes na realidade da sala de aula. Os projetos de extensão vislumbram exatamente esta possibilidade, a de inserir os licenciandos na realidade da sala de aula antes dos estágios obrigatórios, permitindo-lhes a vivência desta realidade.

Inserir os licenciandos na realidade da sala de aula é fundamental no processo de formação docente, pois o professor é um "profissional que está sempre se fazendo" (FARIAS, et al, 2009, p. 55). Além disso, estudos comprovam que o "professor aprende, ensinando; ensina, aprendendo" (FREIRE, 1999). Entendemos que o professor vai se formando professor num processo de vivência e experiência associado à sua formação. Permitir oportunidades em que o graduando entre em contato com a docência é uma forma de garantir que a pessoa vá se tornando um professor, pois "o professor é uma pessoa: e uma parte importante da pessoa é o professor" (NÓVOA, 1992, p. 7).

Como formadores de professores precisamos compreender que a formação é "(...) um dos contextos de socialização que possibilita ao professor reconhecer-se como um profissional, constituindo-se a partir de suas relações com os saberes e com o exercício da docência (FARIAS, et al, 2009, p. 66)".

Para uma formação de qualidade, devemos considerar a formação inicial como uma etapa primordial no processo de formação de professores. Por isso, forjar situações que lhe permitam vivenciar a docência logo no início do curso, "oportunizará ao professor desenvolver 'novas referências que iluminem seu pensamento e, consequentemente, seu agir"' (NÓVOA, 1992, p. 28). 
A formação de professores toma novos direcionamentos com a Pandemia da COVID-19, pois a educação necessita repensar sua prática pedagógica. Aquele plano de aula pensado para o ensino presencial não serve para este momento. Como formadores de docentes somos chamados a levar os licenciandos a repensar a educação nesse cenário, pois a prática docente requer novos processos de aprendizagem e, com isso novos métodos de ensino, novos modos de pensar as componentes curriculares considerando as especificidades, novas práticas avaliativas, novas linguagens e saberes na ação de ensinar precisam ser elaborados. Partindo do princípio de que o professor desenvolve sua atividade profissional na sala de aula, que é o seu espaço escolar, devemos considerar que este espaço sofreu transformações e, consequentemente, as práticas pedagógicas devem ser modificadas. Antes da pandemia, quais os saberes deveriam possuir o profissional da docência, aquele a quem caberia a tarefa de ensinar?

Diversos estudos debatem sobre os saberes docentes, sendo que essa noção vem sendo utilizada em diferentes acepções. Farias (et al, 2009, p. 73) trazem uma síntese desta concepção com base em diferentes autores. Segundo os autores, para Tardif, Lessard e Lahaye (1991) os saberes docentes referem-se a saberes da formação profissional; saberes disciplinares, saberes curriculares e saberes da experiência. Já para Gauthier (1998) os saberes docentes abrangem os saberes disciplinares; saberes curriculares, saberes das Ciências da Educação; saberes da tradição pedagógica; saberes experienciais e saberes da ação pedagógica. Shulman (1986) caracteriza como saberes docentes os saberes advindos do conhecimento do conteúdo da matéria ensinada, conhecimento pedagógico da matéria, bem como o conhecimento curricular. Já para Saviani (1996) o saber docente abrange o saber atitudinal, o saber crítico-contextual, o saber específico, o saber pedagógico e o saber didático-curricular. Pimenta (1999) compreende os saberes docentes como o conjunto dos saberes do conhecimento, saberes pedagógicos e saberes da experiência.

Estudos mais recentes realizados pela Equipe de Pesquisa em História das Ciências da Educação (ERHISE) da Universidade de Genebra, na Suíça, indicam dois tipos de saberes que se articulam na composição dos saberes docentes: os saberes a ensinar e os saberes para ensinar (HOFSTETTER \& VALENTE, 2017). Valente (et al, 2017) refere-se aos saberes a ensinar como aqueles produzidos pelas disciplinas universitárias, pelos diferentes campos científicos considerados importantes para a formação dos professores, ou seja, os conhecimentos relacionados aos conteúdos, já os saberes para ensinar têm por especificidade a docência, ligam-se àqueles saberes próprios 
para os exercícios da profissão docente. Para Hofstetter e Schneuwly (2017) para além do conteúdo em si (saberes a ensinar) o professor mobiliza em sua prática profissional ferramentas do trabalho, como o conhecimento sobre o objeto de trabalho, sobre as práticas de ensino e sobre seu campo de atividade profissional. Nosso entendimento a partir destes estudos é que o professor necessita de ambos os saberes em sua prática docente.

No cenário atual, no âmbito dos saberes para ensinar, podemos inserir um novo saber relacionado às novas práticas de letramento digital que são exigidas tanto dos professores, quanto dos alunos. Isso requer do professor inicialmente um aparato tecnológico (que caso ele não tenha, precisa adquirir), mas também saber lidar com isso, conhecer essas ferramentas que podem viabilizar o ensino remoto. É um novo saber, situado num universo tecnológico, ao qual nem todos estavam acostumados a lidar.

Os saberes para ensinar vão modificando-se pois sofrem influência de fatores externos, que não dependem exclusivamente da atuação do professor. Mais uma vez percebemos a transformação dos saberes profissionais do professor, pois para ensinar nos dias atuais ele necessita mobilizar novas práticas que se adaptem a realidade virtual e remota na qual nos encontramos. Não se trata de abandonar os saberes até então mobilizados para ensinar, mas sim de adaptá-los à realidade atual. Como formadores de docentes temos a obrigação de aproveitar estes momentos e ao adaptar nossas próprias práticas, também incentivar os futuros professores a repensar as práticas pedagógicas e os processos de ensino e aprendizagem.

A experiência do curso, tanto na versão presencial quanto na remota, motivou as coordenadoras a transformá-lo na proposta de um projeto de extensão. Uma vez que a cada início de semestre novos alunos ingressam na UFPR, ofertar uma edição do curso em períodos que coincidam com a chegada desses alunos será uma excelente oportunidade de começar a inseri-los no ambiente acadêmico. Assim, unindo-se às atividades habituais que a universidade promove para receber os calouros, o projeto oportunizará que eles comecem a se habituar com a linguagem matemática específica do ensino superior antes mesmo que iniciem as disciplinas da área de exatas previstas na grade de cada graduação. Pensando na prática docente, o projeto permitirá que os alunos que atuam como ministrantes das aulas interajam em outros aspectos do curso como, por exemplo, na melhoria da apostila que é utilizada durante das aulas, organização e resolução de banco de questões e criação de um site para facilitar o acesso ao material das aulas. Além disso, como o projeto permite que diversas outras atividades de extensão 
sejam vinculadas a ele, será possível desenvolver outras atividades no decorrer do ano incluindo de forma mais efetiva o público externo, principalmente alunos do ensino médio que se preparam para ingressar na universidade. Deste modo, com o projeto será possível que os alunos da licenciatura tenham mais oportunidades de vivenciar a prática docente antes de iniciar os estágios obrigatórios. Tendo em vista que ainda estamos vivenciando a pandemia, o projeto propõe que todas as atividades sejam realizadas de forma remota, enquanto o retorno das atividades presenciais na universidade não for permitido. A motivação para propor o projeto neste ano de 2021 se deve em grande parte à experiência positiva que obtivemos com a execução do curso de nivelamento na sua versão remota. Toda a equipe que participou da elaboração e realização do curso remotamente se dispôs a continuar no projeto, com a certeza de que é possível realizar um trabalho de qualidade mesmo não utilizando as metodologias e recursos que estavam habituados no ensino presencial.

\section{CONSIDERAÇÕES}

A extensão universitária é muito relevante na formação dos estudantes pois permite o contato com a prática antes mesmo dos estágios ou da graduação. Isso em qualquer curso de ensino superior. No tocante à licenciatura, a extensão tem um papel importante pois permite o contato com a docência logo no início do curso, dependendo do interesse dos alunos.

Este curso proporcionou a experiência da docência extracurricular para os futuros professores, incentivando a troca de saberes e preparando-os para o mercado de trabalho, mercado que é completamente passível de transformações e mudanças, como as que vivemos neste momento. As atividades desenvolvidas pelos alunos que ministraram as aulas do curso foram orientadas e supervisionadas pelas coordenadoras, docentes da Universidade, que auxiliaram no processo de formação destes alunos enquanto futuros professores, o que permitiu um diálogo constante entre licenciandos e coordenadoras na estruturação da proposta. Além disso, uma vez que o curso abordou conceitos matemáticos que são pré-requisitos para o bom desempenho acadêmico nas disciplinas de matemática, esta proposta colaborou diretamente para a formação profissional dos alunos participantes. Os licenciandos foram desafiados a desempenhar a teoria na prática, buscando formas de como ensinar a matemática que já conheciam, como transformar os conteúdos para que os participantes pudessem entender, e tudo isso de uma forma nova 
para eles, a forma remota, que até então não fazia parte da realidade. Os ministrantes puderam ocupar simultaneamente dois papéis no ensino remoto. Por um lado, estavam cursando suas disciplinas e vivenciando as dificuldades de seus professores na adaptação das aulas remotas. Por outro lado, se colocaram na posição daquele que precisar ensinar, de quem precisa refletir sobre como o outro compreenderá o que é transmitido e se essa compreensão fará sentido. Além disso, puderam passar pela experiência de ter que readequar a aula para uma situação que não estava prevista. Dentre todos os desafios do ensino remoto, destaca-se como os fatores externos podem interferir na condução da aula, pois este formato de ensino depende necessariamente da conexão com a internet. Condições meteorológicas adversas poderiam impedir que os alunos, participantes e ministrantes, se conectassem ao endereço eletrônico no momento da aula. Esta situação ocorreu durante o desenvolvimento do curso duas vezes e em ambas os alunos ministrantes assumiram prontamente o papel que o docente precisa ter em sala de aula: decidir e mediar.

Embora os ministrantes contassem com um material para nortear as aulas, a forma como os conteúdos foram trabalhados ficou a cargo de cada equipe. Foi necessário que se dedicassem a elaboração, pesquisa e organização de como os assuntos seriam abordados. Para as coordenadoras, observar a maneira diversificada e criativa com que as aulas foram pensadas pelos ministrantes intensificou a ideia de que é fundamental colocar os licenciandos na prática docente e que não é necessário que eles estejam nos semestres finais da graduação para que o trabalho seja realizado com êxito.

Dentre os sete alunos que ministraram as aulas, alguns estão nos últimos semestres da graduação, outros estão iniciando a segunda metade do curso e outros estão na universidade há pouco mais de um ano. Neste sentido, foi possível proporcionar vivências muito diferentes para cada um deles e o fato de terem trabalhado em equipe fez com que a troca de experiências fosse ainda mais enriquecedora.

O curso impactou na formação dos estudantes que participaram do mesmo, pois buscou fortalecer e facilitar o desempenho destes nas passíveis dificuldades que apresentavam nas disciplinas relacionadas às áreas de exatas, contribuindo para a formação acadêmica. Na proposta inicial do curso, ainda no formato presencial, existia uma grande preocupação em atender os alunos que estavam ingressando na universidade para que as dificuldades nas disciplinas de matemática não fossem um fator de desmotivação para a permanência na graduação que haviam escolhido. Com a pandemia e, consequentemente, a suspensão do calendário acadêmico, esta preocupação se tornou 
ainda maior pois as dificuldades que estes alunos apresentariam nas disciplinas que seriam ministradas remotamente poderiam ser potencializadas. Sendo assim, a readaptação do curso para a versão remota tentou suavizar, ainda que de forma discreta, alguns impasses que os alunos recém ingressantes na universidade poderiam encontrar nas disciplinas de matemática que também estavam sendo ofertadas remotamente.

\section{REFERÊNCIAS}

FARIAS, Isabel Maria Sabino. [et al.]. Didática e docência: aprendendo a profissão. Brasília: Liber Livro, 2009.

FREIRE, Paulo. Pedagogia da autonomia: saberes necessários à prática educativa. $13^{\text {a }}$ ed. São Paulo: Paz e Terra, 1999.

HOFSTETTER, Rita; SCHNEYWLY, Bernard. Saberes: Saberes: um tema central para as profissões do ensino e da formação. In R. Hofstetter \& W. R. Valente (Orgs.). Saberes em (trans) formação: tema central da formação de professores (Coleção Contextos da Ciência, pp.113-172, trad. Viviane Barros Maciel e Wagner Rodrigues Valente). São Paulo: Editora Livraria da Fïsica, 2017.

HOFSTETTER, Rita; VALENTE, Wagner Rodrigues. Saberes em (trans)formação: tema central da formação de professores. 1a ed. - São Paulo: Editora Livraria da Física, 2017.

RONDINI, Carina Alexandra; PEDRO, Ketilin Mayra; DUARTE, Cláudia dos Santos. Pandemia da COVID-19 e o Ensino Remoto Emergencial: mudanças na prática pedagógica. In: Interfaces Científicas. Aracaju. V. 10. n.1. p. 41-57. Número Temático - 2020.2 Disponível em: https://periodicos.set.edu.br/educacao/article/view/9085/4128. Acesso em março de 2021. 
NÓVOA, Antônio. (org.). Vidas de Professores. Portugal: Porto Editora, 1992.

VALENTE, Wagner Rodrigues; BERTINI, Luciane de Fátima; MORAIS, Rosilda dos Santos. Novos aportes teórico-metodológicos sobre os saberes profissionais na formação de professores que ensinam Matemática. In: Acta Scientiae. Canoas. v. 19. n. 2. p. 224-235. Mar./abr. 2017. Disponível em: http://www.periodicos.ulbra.br/index.php/acta/article/view/2816/2299. Acesso em março de 2021.

ZANCAN, Sabrina. Método líquen: uma proposta para auxiliar o ensino de aritmética nos anos iniciais. Tese de Doutorado. Programa de Pós-Graduação em Educação em Ciências: Química da Vida e Saúde. Universidade Federal de Santa Maria. Santa Maria, 2017. Disponível em: https://repositorio.ufsm.br/handle/1/14111. Acesso em março de 2021.

Recebido em: 19 de março de 2021.

Aceito em: 11 de maio de 2021. 